\title{
GUERRA Y CONCIENCIA NEGATIVA EN LA CONSTRUCCIÓN HISTÓRICA DEL REINO DE CHILE
}

\author{
Luz Ángela Martínez \\ Universidad de Chile, Santiago de Chile, Chile \\ luzmartine@gmail.com
}

\section{RESUMEN / ABSTRACT}

Este trabajo explora el espacio escritural existente entre la ficción, la autobiografía, el discurso político y el discurso histórico en las circunstancias específicas de escrituras coloniales chilenas, cuyo tema es la guerra que funda la escritura e informa la subjetividad que escribe. A propósito de Cautiverio feliz... de Francisco de Pineda y Bascuñán, el trabajo propone que la superposición entre subjetividad, historia, escritura y guerra configura en las letras coloniales chilenas una "historia de la conciencia" fundada en la negatividad crítica, de tal manera que la puesta en relato de la guerra de Chile expone una historia de la Historia Moderna.

Palabras clave: guerra de Chile, conciencia negativa, Historia Moderna.

\section{WAR AND NEGATIVE CONSCIOUSNESS IN THE HISTORICAL CONSTRUCTION OF THE KINGDOM OF CHILE}

This work explores the textual space between fiction, autobiography, political discourse, and historical discourse in the specific circumstances of Chilean colonial texts, where the theme of war functions as a basis for the text and informs its subjectivity. With regard to Francisco de Pineda y Bascuñan's Cautivero Feliz..., this piece proposes that the overlap between subjectivity, history, scripture, and war, figures in Chilean colonial dialogues as a "history of consciousness" founded in critical negativity, in such a way that the narrative setting of the War of Chile exposes a story of Modern History.

KEYWORDS: War of Chile, negative dialectics, modern history. 
El desastre oscuro es el que porta la luz Maurice Blanchot ${ }^{1}$

¿Documento histórico, etnográfico, relación política, crónica, memorial, autobiografía o pesada novela de estructura barroca? Todas estas denominaciones y más han merecido Cautiverio feliz, Del Maestre de Campo General Don Francisco Nuñes de Pineda. Y rason Individual, de las Guerras Dilatadas, del Reyno, de Chille. Compuesto Por él mismo. Y dedicado Al Rey Nuestro Señor, Don Carlos, Segundo que Dios guarde muchos años para gloria $N_{\text {Nustra }}{ }^{2}$, una obra centrada en las razones que hicieron interminable la guerra fundacional de Chile en la primera fase colonial de la era moderna, tanto como en la subjetividad que la protagoniza y padece: la subjetividad criolla, informada por esa guerra.

Más allá de la discrepancia o acuerdo a que ha llegado la crítica ${ }^{3}$, proponemos que la sincronía entre guerra fundacional y subjetividad en esta obra lleva la definición del género a un nivel de problematicidad mayor que la propiamente

1 Maurice Blanchot. La escritura del desastre. Traducción de Cristina Peretti y Luis Ferrero Carracedo. Madrid: Editorial Trotta, 2015, p. 12.

2 Francisco Núñez de Pineda y Bascuñán. Cautiverio Feliz. Ed. Mario Ferrecho y Raïssa Kordić Riquelme. Estudio preliminar de Cedomil Goic. Biblioteca Antigua Chilena, Facultad de Filosofía y Humanidades, Universidad de Chile, Santiago, 2001.

3 Son muchos los autores involucrados en la discusión. Citamos solo algunos. Mario Rodríguez Fernández. "Azar, pormenor, seducción y poder en Cautiverio Feliz. Revista Chilena de Literatura 61 (2002): 39-60. Raquel Chang-Rodríguez. "Conocimiento, poder y escritura en el Cautiverio Feliz". Violencia y subversión en la prosa colonial hispanoamericana. Siglos XVI y XVII. Madrid: Porrúa, 1982. 63-83. Gilberto Triviños. "Punctum y común parecer en el Cautiverio Feliz". Cánovas, Rodrigo y Roberto Hozven. Crisis, apocalipsis y utopías. Fines de siglo en la literatura latinoamericana. Santiago de Chile: Ocho Libros, 2000. 494-498; "No os olvidéis de nosotros: martirio y fineza en el Cautiverio Feliz". Acta Literaria 25 (2000): 81-100; José Anadón. Pineda y Bascuñán, defensor del araucano. Vida y escritos de un criollo chileno del siglo XVII. Santiago de Chile: Editorial Universitaria, 1977; Prosistas coloniales del siglo XVII: Rosales y Pineda Bascuñán. Santiago de Chile: Seminario de Filología Hispánica, 1978. "Estudio preliminar". Núñez de Pineda y Bascuñán, Francisco. Suma y epílogo de lo más esencial que contiene el libro intitulado "Cautiverio feliz, y guerras dilatadas del Reino de Chile”, ed. J. Anadon y R. A. McNeil. Santiago de Chile: Sociedad Chilena de Historia y Geografía/Ediciones Universidad Católica de Chile, 1984. 13-31. Lucía Invernizzi Santa Cruz. "Recursos de la argumentación judicial-deliberativa en el Cautiverio feliz de Pineda y Bascuñán". Revista Chilena de Literatura 43 (1993): 5-30. Sergio Correa Bello. El Cautiverio feliz en la vida politica chilena del siglo XVII. Santiago de Chile: Andrés Bello, 1965. 
literaria, pues implica la cuestión de la verdad y la subjetividad, y las deja boyando entre dos campos de estudio distintos respecto de la construcción e inteligibilidad del pasado: la historiografía y los estudios literarios chilenos. Dos campos, por cierto, que no terminan de asumir en ciertas obras los confusos lindes entre literatura e historia ${ }^{4}$, entre poesía y política, entre lo particular de una existencia y lo universal de la historia de la humanidad, y que por ello experimentan su mutua cercanía como una amenazante aporía de la verdad.

Acontece, sin embargo que, cuando una obra propone una coincidencia entre el "sentido de una subjetividad" y el "sentido de la historia", se presenta a sí misma como una "historia de la conciencia" y cobra inmediato interés filosófico y universal, en tanto la función otorgada a la escritura es poner "la conciencia ante sí" en el tiempo (Ricoeur, Historia y Verdad, 44). Esta coincidencia es la que propone la obra que nos ocupa y a la luz de aquello todo parece sugerir que no se trata ya de dirimir si al leer Cautiverio feliz... estamos frente a una novela, la crónica de una guerra interminable u otro tipo genérico, sino de interrogar el in-acotado -y quizá in-acotable- espacio escritural existente entre la ficción, la autobiografía, el discurso político y el discurso histórico en las circunstancias específicas de escrituras coloniales chilenas, cuyo tema es la guerra que funda la escritura e informa la subjetividad que escribe. La superposición entre subjetividad, historia y escritura, y la "historia de la conciencia" que proponen las letras coloniales, nos lleva más bien a preguntarnos qué tipo de sujeto, qué tipo de mundo y circunstancia requieren de la hibridación total de los géneros para expresarse y ser expresados. A preguntarnos también si la crisis del género provocada por la puesta en relato de la guerra de Chile expone una historia de la Historia, de la Historia Moderna.

4 Revisar en: Andrés Bello (1862). "La araucana por don Alonso de Ercilla i Zúñiga - Juicio crítico de esta obra por el Señor Rector de la Universidad don Andrés Bello". Anales de la Universidad de Chile, doi: 10.5354/0717-8883.2010.2476. Hayden White. El texto literario como artefacto histórico. Barcelona: Ediciones Paidós, 2003. Paul Ricoeur. Historia $y$ verdad. Buenos Aires: Fondo de Cultura Económica; 2015. 


\section{GÉNERO LITERARIO Y CRISIS DE SENTIDO HISTÓRICO}

El título completo de Cautiverio feliz... convoca simultáneamente tres tipos discursivos distintos y propone tres ejes de lectura desde los cuales "el pío lector" puede abordar la obra: el género autobiográfico, el tratado político y el discurso histórico. De tal manera, que desde su inicio la obra de Núñez de Pineda y Bascuñán se presenta al lector como un dispositivo discursivo complejo, actualizado por una particular enunciación de carácter múltiple, que entrelaza una sola unidad de sentido en tres tipos distintos de relato y pone en juego tres pactos de lectura: el relato de un acontecimiento de la vida personal (el cautiverio); un tratado político (el análisis de una situación político-administrativa dirigido al gobernante ${ }^{5}$; y la explicación histórica de la guerra de Chile, subrayada esta última como razón individual y composición o escritura propia ("Compuesto por él mismo"). Esto es, en resumen, como pensamiento y escritura de un sujeto que desde su experiencia (experiencia del "yo"), discernimiento (análisis crítico) y localización en la estructura política-administrativa colonial (Maestro de Campo General, criollo ${ }^{6}$ ), dirige un discurso a la autoridad (el monarca implicado por la condición moral del "pío lector") y le presenta una reflexión sobre la historia. Esta disposición, sin duda, señala una estructura o construcción compleja comprometida con las distintas formas de codificar la experiencia múltiple del yo. Es decir, indica la presencia de una subjetividad compleja que requiere de una estructura sui generis para expresar su experiencia de la guerra y para presentarla en la escritura como una historia de la Historia.

La sincronía entre el "sentido de la subjetividad" y el "sentido de la Historia" se convierte en notoria insistencia en el "Proemio al Lector" de la Suma y Epílogo de lo mas esencial, que contiene el Libro titulado Cautiverio feliz, y guerras dilatadas del Reyno de Chile...7 Ahí lejos de establecerse

5 La destinación de la obra se inscribe en las prácticas sociales del vasallaje, de tal manera que las prácticas escriturales se corresponden con el universo simbólico de la monarquía. De ahí la importancia de un discurso político que pone en entredicho la solvencia moral y espiritual de aquella.

6 La denominación, indio, mestizo, mulato, criollo, español, además de convertirse en la colonia americana en una forma de identificación de los sujetos, era un dispositivo de adscripción y repartición de los sujetos a la estructura social y al sistema económico coloniales. A este respecto, son bien conocidos los cuadros de castas de la Colonia.

Ver en Núñez de Pineda y Bascuñán, Tomo I. 
una supremacía de alguno de los tipos discursivos presentes en el título, estos se confunden aún más como consecuencia de la acentuación del "yo" de la enunciación y de las funciones que se le asignan a lo largo de las dos partes que configuran la obra total. Una, quizás la más importante para la "historia de la conciencia", es la de operar como el elemento textual común que actualiza los tres tipos discursivos mencionados, de tal manera que el relato de la vivencia personal biográfica, "la historia del feliz cautiverio", es al mismo tiempo la explicación del hecho histórico, la guerra, como también es lo que autoriza al sujeto para hablar al monarca de $s u$ mal gobierno: el cautivo tiene derecho a hablar y desde esa posición despojada testifica ${ }^{8}$ ante la autoridad. De tal manera que el yo puesto en relato es la sustancia que nutre el juicio político y moral sobre los hechos, y también el dispositivo que desata ${ }^{9}$ el discurso político sobre la historia, dándole un objetivo: "manifestar y dar a entender las causas y fundamentos" ( Núñez de Pineda, Tomo I, 73) de la catástrofe social, la guerra, experimentada por el sujeto como horizonte de la historia. Todo esto compone lo que podríamos llamar, un acontecimiento -una experiencia única- en tanto el yo del cautivo puesto en relato viene a ser, al mismo tiempo, la puesta en relato de la Historia del Reino de Chile y de las "austriales Indias" ( Núñez de Pineda, Tomo I, 73), ambos territorios cautivos ${ }^{10}$ también por la guerra. Sujeto y Reino padecen entonces la misma condición; una misma catástrofe los recorre y configura, los consume y los fusiona en una sola narración. De tal manera que aquí la inscripción de la biografía en el relato de la historia se nos presenta como el trabajo necesario (casi desesperado) de la subjetividad criolla sobre la masa devoradora de los hechos, para salvarse o perderse con su patria. Salvarse

\footnotetext{
Respecto de esta condición del testigo, Paul Ricoeur dice lo siguiente, “... la afirmación originaria tiene algo definitivamente inaugural y concerniente a la idea de que el yo se hace a sí mismo. Esta afirmación originaria por ningún motivo es una experiencia para una filosofía reflexiva; aunque numéricamente idéntica con la conciencia real en cada uno, es el acto que realiza la negación de las limitaciones que afectan el destino individual. Es despojo" (Ricoeur, Texto... 10).

Utilizo el término desatar en los sentidos de "destrabar", y “desacoplar", en cuanto la puesta en relato del yo es lo que "desencadena" un juicio moral de la conquista de Chile sin precedente. Ese juicio, se desacopla del discurso heroico de la hazaña espiritual, bélica y esforzada ("los trabajos del hambre") de la guerra contra los pueblos originarios de Chile.

10 "Pueblos expuestos siempre a desaparecer", en el sentido de George Didi-Huberman. Pueblos expuestos, pueblos figurantes, 2014.
} 
o perderse también en un sentido ético, porque no hay ninguna guerra que siendo perpetua pueda ser justa.

Habiendo trabajado algunos meses y días, pío lector, en la historia de mi feliz cautiverio con intención fervorosa de manifestar y dar a entender las causas y fundamentos que se hallan para que esta guerra de Chile sea inacabable y perpetua, por las ciertas noticias que adquirí cuidadoso, estando preso y cautivo entre los indios antiguos, nacidos y criados en aquellos tiempos que principiaron esta conquista nuestros antepasados españoles, y por las experiencias largas que más de cuarenta años efectivos de estas fronteras me han participado... (Tomo I, 73)

Si atendemos a las problemáticas que plantea Cautiverio feliz..., bien podemos pensar que en el ámbito de la literatura colonial chilena el asunto del género no se limita a una mera discusión literaria, en la medida en que implica una "historia de la conciencia" y una memoria de la guerra en la fundación de dicha conciencia. Esta afirmación cobra un sentido mayor si recordamos que la crítica alguna vez habló de La Araucana de Alonso de Ercilla como de una "crónica rimada" (Invernizzi 230), y si incorporamos la dimensión política tan recurrida en los poemas del ciclo araucano, Purén Indómito, Arauco domado, La guerra de Chile. En cualquier caso, si atendemos a esa mixtura, La Araucana sería una crónica rimada de la guerra y la exposición de una conciencia totalmente afectada por su violencia, llevada por ella a la negatividad histórica. De tal manera que desde el siglo XVI la cuestión del género exhibe las formas en que lo poético se aproxima al horror y lo establece en la memoria fundacional de la historia moderna chilena. Por eso no es de extrañar que la mixtura genérica involucre y manifieste una crisis en la construcción de sentido en el inicio de la modernidad en Chile, particularmente afectada por una guerra que se percibe como perpetua.

En este caso en particular, la enunciación múltiple de Cautiverio Feliz del Maestro de Campo General Don Francisco Núñez de Pineda... construye una visión de la historia y presenta una versión de ella en la cual el sujeto de la escritura autobiográfica y el sujeto del discurso histórico se identifican en un sentido fuerte ${ }^{11}$, y esa identificación anula la distancia entre la experiencia 
vital y los hechos políticos de un periodo determinado. La consecuencia más relevante de esa identificación es que anula la desproporción entre lo inconmensurable del tiempo histórico y el tiempo limitado del sujeto, pues los cuarenta años de vida consumidos por la guerra, y solo ellos (o solo la intensidad de esa consunción), pueden dar cuenta de lo "inacabable y perpetuo", terrible, lo sin fin en la historia: la guerra.

[...] el principal blanco a que se encaminan mis discursos no es otro que hacer las verdades patentes; con que daremos principio a mi Cautiverio feliz, de adonde sacaremos el fundamento de la dilación de esta guerra de Chile, pues lo uno y lo otro viene a ser directo blanco de este libro (Tomo I, 240).

\section{SUJETO Y NEGATIVIDAD}

Si para el orden colonial chileno lo anterior es naturalmente significativo, respecto de la configuración del sujeto es importante señalar que esta identificación entre la vida privada y lo público afecta la interioridad del sujeto y su visión de mundo, pues de ese estado de afección surge una suerte de agonista histórico, de conciencia negativa identificada con la catástrofe histórica que acontece en un determinado territorio: “...no será mucho que peresca Chile y con él los que le habitamos...” (Tomo II, 773).

Tal conciencia articulada por la negatividad se localiza discursivamente en el borde más exterior del sistema monárquico y más excéntrico del principio que organiza y ordena políticamente la cristiandad: la justicia. Conciencia, en definitiva, que percibe y padece en ese borde la caducidad de ese principio organizador y que metaforiza su consunción como oscuridad, caos y enfermedad:

Sacra real majestad, de tal suerte en estos lastimosos tiempos se ha señalado la cautelosa malicia, avasallando la justicia y la razón, que es delicto grande promulgar verdades, y cuanto más dilatados nos

de esta edad senté plaza de soldado por orden y gusto de mi amado padre, que cuidó primero de darme la educación y enseñanza que deben dar los padres a los hijos; pues, habiendo quedado de cinco a seis años, me entregó, me entregó a los padres de la Compañía de Jesús; porque de tan tierna edad quedé sin madre..." (75). 
hallamos de los resplandecientes rayos del sol universal que nos alumbra, como lo es vuestra real majestad de toda su monarquía, tanto más son las nieblas tenebrosas que las cubren; a cuya causa en estos reinos remotos de las Indias van de mal en peor sus menoscabos, por no haber quién se atreva a descubrirlas, antes sí las ocultan y solapan (63).

En tanto criolla, se trata de una conciencia sin otra posibilidad que definir, delimitar y afirmar su identidad en el no-ser implícito de la diferencia, no-ser indio, no-ser español, pero que desde la percepción perturbadora de una doble negación identitaria articula su interpretación de los hechos, su visión de mundo y los mecanismos para intervenir en él. En este caso, doble negación, interpretación e intervención, se constituyen mediante un solo elemento: la escritura como tal, como escritura del yo (autobiografía) y como reescritura de la historia. O si se quiere, conciencia que se configura por negatividad, pero que se exterioriza y emerge en la escritura para decir "Yo" ante la historia: el criollo.

Aun hay más que decir sobre la construcción negativa de la identidad en esta obra. Si bien su destinación a la Sacra y Real majestad de Nuestro Católico Rey y Señor Carlos II inscribe explícitamente el discurso de Núñez de Pineda y Bascuñán en las prácticas escriturales y simbólicas de la monarquía, no es la única relación de vasallaje asumida por la voz enunciante de la obra. Tal como expone la dedicatoria, desde un principio se percibe otro lazo que la conciencia enunciante no solo reconoce tan propio como el que mantiene con el monarca, sino que, además, es comunicado al mismo monarca. Esa relación es con la "chilena patria", a la cual la conciencia se siente unida como a un destino peligroso.

Movido, pues, señor muy poderoso, del celo que me asiste y acompaña por fiel y leal vasallo de vuestra majestad suprema y de hijo natural desta chilena patria, quice padecer calumnias de atrevido y arrojarme al naufragio valeroso, que tal vez favorece la fortuna a los que temen los peligros (63).

Este doble vasallaje, a lo particular propio de la patria y a lo general distante de la monarquía, introduce una serie de tensiones en todos los niveles de la obra, en sus dimensiones bélica, política, simbólica y discursiva, así como en la conciencia del sujeto. Estas tensiones se producen porque el criollo percibe que entre una dimensión y otra, la patria y la monarquía, los lazos están cortados, 
son muy débiles o están corruptos (aquí no hay justicia, aquí no es posible la verdad), de manera que en muchas aspectos medulares no existe una identidad entre una y otra, en cuanto no existe una relación de identificación a través del vínculo entre la Capitanía de Chile (la "chilena patria") y el Virreinato del Perú en representación y actualización la monarquía. El desprendimiento de la parte del todo tiene, por supuesto, importantes consecuencias. Diremos, en primer lugar, que ahí se encuentra el germen específico de la conciencia criolla chilena y su irremediable sentimiento de distancia, desprendimiento y pérdida de un todo simbólico que alguna vez pudo ser. Si en el orden del discurso, el doble vasallaje construye, organiza y mueve retóricamente la obra, el desprendimiento de la patria del todo simbólico de la monarquía, nutre el ethos y el pathos del discurso político de la obra.

El Proemio ya citado indica al pío lector que la potencia asignada a la historia personal para explicar la historia radica en este caso en que el sujeto cautivo es el portador de un tipo de conocimiento que no le es dado a otro que no haya pasado por una doble experiencia: la de estar preso y cautivo. Esto es, estar privado de libertad, al borde de ser esclavizado, como hacía el bando hispánico-criollo con los sujetos mapuche; luego, haber experimentado ese singular estatuto de ser precario, transitorio, altamente propenso al mestizaje ${ }^{12}$ y, por lo tanto, sospechoso (más cuando se trató de mujeres), que adquirieron algunos sujetos hispanizados retenidos e incorporados a la comunidad indígena en la frontera chilena de la guerra de conquista: la experiencia de ser cautivo. Pero también cautivo en el significado religioso cristiano del amor, y además en el sentido del rendimiento del esclavo al amo virtuoso. En este caso, el amo virtuoso indio, como resalta Cedomil Goic en el prólogo de la versión que manejamos (Tomo I, 12) ${ }^{13}$.

Al citar la experiencia como fundamento del discurso podemos pensar, un tanto a la ligera, que Núñez de Pineda y Bascuñán se ampara en un motivo bastante recurrido por los sujetos de la época y por ello podemos pasar por alto el tipo particular al cual se refiere y el tipo de conocimiento

12 El asunto de la proximidad y divergencia entre el criollo y el mestizo implica una filosofía del ser. Si, como dijimos, el criollo representa una identidad perturbada por el no-ser, en el espectro identitario colonial, la condición de mestizo fue percibida como la "catástrofe del ser" tanto por el sujeto europeo cristiano que sostiene la "pureza de sangre" como por el sujeto indígena. Guamán Poma es un ejemplo de aquello.

13 Ver "Romance En Agradecimiento a Muliacán mi Amo, Debido a sus Agasajos y Corteses Acciones" (13). 
que esta participa. En este caso, aquello "participado" por la experiencia es el reconocimiento de

la dolencia y el lastimoso achaque de que se haya no poco lastimado nuestro afligido reino; y, porque cada día en peor estado veo sus ruinas, originadas de los estilos de gobierno que de algunos superiores ministros del rey, nuestro señor, no tan solamente en este reino de Chile, sino también en todas estas austriales Indias... (Tomo I, 73).

En el marco general de las Indias, la experiencia referida es la de habitar el cuerpo enfermo del virreinato y padecer ahí la corrupción del cuerpo político de la monarquía cristiana, cuyo referente último es el cuerpo enfermo del monarca $^{14}$. En el ámbito de lo particular-individual, se trata de la experiencia directa de una guerra que la conciencia percibe sin fin y que configura a lo largo de toda la obra un ethos de la ruina. Por supuesto este ethos participa al sujeto un tipo de saber: el conocimiento de un mundo devastado en su origen, "el nuevo mundo", que surge arruinado y avanza cada día hacia su mayor destrucción.

Ciertamente, se puede instalar el sentimiento vital de Núñez de Pineda en la corriente quevediana del soneto "Miré los muros de la patria mía", sin embargo, la costumbre de asimilar la cosmovisión del americano a la tradición peninsular solo ha conseguido desdibujar ambas. Desde la Roma pagana hasta el imperio católico, Quevedo se lamenta por una civilización que tuvo una "edad dorada" y que el tiempo desplomó. Con la mirada vuelta hacia atrás, la voz poética pierde el presente y se sumerge en la melancolía por lo que se tuvo, por lo que se creyó tener y se perdió. La ruina de Núñez de Pineda, en cambio, es aquella que en el presente se muestra como lo "non nato"; lo que se anuncia pero nunca llega a ser, porque la anunciación porta en sí misma el germen de la destrucción y el lugar de lo prometido lo ocupa el escombro de una promesa. El sentimiento que la acompaña no es melancólico ni vuelto al pasado, como el de Quevedo y del barroco europeo en general ${ }^{15}$. Es explosivo, vociferante, rabiosamente arraigado a la insoportable visión

14 Para este tema, Ernst H. Kantorovicz, Los dos cuerpos de rey. Un estudio de teología política medieval. Trad. Susana Aikin Araluce y Rafael Blazquez Godoy. Madrid: Akal, 2012; A. Corbin, J. J. Courtine y G. Vigarello, "El cuerpo del rey". Historia del Cuerpo. Del Renacimiento al Siglo de las Luces. vol. I. Madrid: Taurus, 2006. 373-380.

15 Para una visión general, W. Benjamin, El origen del Trauerspiel alemán. Buenos Aires: Gorla, 2012. 
del presente y a un territorio obsesivamente invocado a lo largo de toda la obra: Chile, metonimia de las Indias y ambos metonimias de la devastación. Así como la obra nos habla de un "cautiverio feliz" en el territorio indígena, asimismo configura el oxímoron "ruina del nuevo mundo" en el lado del mundo global moderno, de manera que ya no se trata de la melancolía, sino del malestar que se experimenta tan profundamente en "las Américas" (en plural, como las llama, Pineda) y en especial en el Reino de Chile. Tal es el conocimiento que le ha participado la experiencia a esta sujeto nacido en las Indias Austriales y el sentimiento vital que le da todo el impulso a la obra: el desencanto furioso del americano.

\section{PROFECÍA Y PRESENTE}

Desde luego que un sujeto americano del siglo XVII tramita su malestar según los recursos que le ofrece su tiempo y su circunstancia. El de Núñez de Pineda, enorme y consciente de la precariedad enunciativa a la que lo confina su condición fronteriza-criolla, necesita sin embargo traspasar la distancia y el aislamiento de la frontera - "las nieblas tenebrosas" que la cubren-, para inscribirse en el campo discursivo y simbólico en el que se debatían los asuntos concernientes a la política del "nuevo mundo": la policía cristiana y su justificación evangélica. En este sentido, las Sagradas Escrituras le proveen de un recurso incuestionable para poner a la "clara luz del desengaño la obscura confusión con que se rigen y gobiernan estos remotos reinos de las Indias" consumidos por una guerra que enmascara su corrupción bajo el discurso de la "guerra santa"16. Es por eso que imposta el lugar de enunciación del "profeta santo" y como tal levanta un discurso condenatorio:

16 La prolongación de la "guerra santa" sobre el nuevo mundo se formula de la siguiente manera: "Quiso Dios descubrir las Indias en vuestro tiempo y a vuestros vasallos, para que los convirtiésedes a su santa ley, como dicen muchos hombres sabios y cristianos. Comenzaron las conquistas de los indios acabadas la de moros, por que siempre guerreasen españoles contra infieles; otorgó la conquista y conversión el papa; tomaste por letra Plus ultra, dando a entender el señorío de Nuevo Mundo. Justo es, pues, que vuestra majestad favorezca la conquista y los conquistadores, mirando mucho por los conquistados". López de Gómora 5. Las cursivas son nuestras. Ver también, Adeline Rucquoi. "De los reyes que no son taumaturgos: los fundamentos de la realeza en España". Relaciones. Estudios de Historia y Sociedad. Colegio de Michoacán. Vol. XIII, 1992. 55-100. 
Y para que con más claridad y menos dilaciones puedan los curiosos lectores ser dueños del fundamental asumpto, encaminado a manifestar verdades claras y patentes, arrebatado del ardiente celo que me asiste, a imitación de aquel profeta sancto que celaba la honra y la gloria de Dios; $y$, aunque por la verdad clara y descubierta me combatan y cerquen las rigurosas tormentas $[\ldots](73)$.

Bien sabemos que el lugar de enunciación modela la imagen de quien enuncia, la precede, la intenciona y la proyecta hacia el pasado y el futuro de una red cultural y expresiva determinada. También sabemos que hay actualizaciones que desencajan el modelo enunciativo bajo el cual se amparan o en cual se originan. En este sentido, la apropiación de la "altura profética", anclada sin embargo por la fuerte marca autobiográfica del "Yo" al presente, a la experiencia y al debate político-ideológico, lleva a preguntarse por la índole aparentemente contradictoria de esta apropiación en una obra que trata de la guerra. Pero sobre todo, por el horizonte temporal que esa apropiación genera.

Si atendemos al conocimiento participado por la ruina y atendemos también que la catástrofe histórica se relata en el momento que está sucediendo, en el presente de la guerra, resulta que la imagen que se compone no es la del "profeta santo", sagrada y atemporal, sino otra más bien desajustada del modelo con que busca disimular su atadura al devenir del presente catastrófico y la urgencia de sus necesidades expresivas, ajenas del todo a la a-historicidad trascendente que corresponde al comunicado de Dios: el malestar político, la denuncia del proceso histórico, la frustración del sujeto. Se trata de una voz enunciativa localizada en el punto de descalce entre la "Historia Sagrada" y la historia real de la cristiandad, asimismo, en el descalce entre el discurso de la guerra santa-justa y la experiencia de la guerra injusta-corrupta de la conquista. Ciertamente, esto afecta el orden del sujeto cristiano criollo, pues se presenta como un sujeto en discrepancia por una parte y en carencia por otra $^{17}$, pues la fe a la que recurre para tramitar los asuntos del alma no le alcanza para solventar el caos de su presente histórico:

17 "Observemos primero la idea de discrepancia y de parte. No se atestigua sino allí donde hay disputa entre partes que litigan una contra la otra, constituyendo proceso; razón por la cual el testimonio procede como prueba a favor o en contra de las partes y sus tesis. Esta noción de discrepancia y de partes es eminentemente generalizable. Se extiende a todas las situaciones en las cuales un juicio o una situación pueden ser llevados hasta el término de un debate, de una confrontación entre posiciones adversas y puntos de vista adversos" (Ricoeur, Texto..., 16). 
¿Cómo desís los españoles que las iglesias no son mas de para rezar y decir misa en ellas?, y sois unos embusteros, aunque perdonéis, capitán, porque no servían los templos de otra cosa que de ser capa de semejantes maldades [...] (668).

Así pues, a pesar de la fe, este es en el horizonte del descreimiento respecto de la institución religiosa en el cual despunta la conciencia moderna chilena $y$ en el cual se observar la fractura de los principios que hasta ese momento sostenían la ideología de la conquista: la asociación entre la monarquía y la cristiandad (el español es el cristiano y viceversa), la comunión entre poder terreno y el divino por el ejercicio de la justicia y la guerra santa que lleva adelante esa justicia. Localizado entonces en el fin de la utopía americana de la cristiandad, Pineda encarna la figura barroca del "desencanto histórico", tanto como en el orden del discurso representa la conciencia desamparada moderna que asume la catástrofe y decide dar "razón individual" de ella. En suma, ya no se trata del hombre como instrumento del mensaje de Dios, el profeta, sino de la razón individual del sujeto que experimenta la historia como catástrofe política y busca desesperanzadamente intervenir en ella. De su lúcida desolación va a surgir el proyecto de gobierno que puede poner fin a la guerra injusta y corrupta. Y de la misma actitud mental se desprende la visión de mundo que la escritura dona al "pío lector" y al futuro del Reino de Chile: un tipo de saber, o más bien una pregunta, en palabras de Maurice Blanchot.

El desastre es el don, da el desastre: es como si se hiciese caso omiso del ser y del no-ser. No es advenimiento (lo propio de lo que llega) -no llega, de modo que no llego a ese pensamiento, salvo sin saberlo, sin la apropiación de un saber. ¿O acaso hay advenimiento de lo que no llega, de lo que vendría sin llegada, fuera de ser y como por deriva? ¿El desastre póstumo (10).

\section{CONCIENCIA MODERNA Y RUINA}

Ciertamente es una opinión común considerar a los sujetos de los siglos XVI y XVII como sujetos "premodernos", ajenos a la contradicción, al escepticismo y a la soledad de la razón individual frente al desarrollo histórico. Ciertamente, esta opinión debe ser revisada a la luz de lo expuesto en Cautiverio Feliz..., pues contrariamente a lo que se puede pensar de un discurso que atrae 
constantemente citas de los "sabios santos", este introduce una serie de operaciones que actúan corrosivamente al interior de la "policía cristiana", cuyo objetivo principal es la derogación de la autoridad espiritual de la primera cristiandad involucrada en la guerra de conquista de Chile. Dimensionar los alcances de estas operaciones permite observar un conjunto de elementos que nos hablan de la crisis como elemento central en la conciencia barroca chilena de la primera fase colonial de la modernidad.

El primer indicio notable de la desautorización del proceso se establece en el Proemio ya citado. Ahí, Pineda anuncia que las noticias que va a entregar las adquirió "[...] entre los indios antiguos, nacidos y criados en aquellos tiempos que principiaron esta conquista nuestros antepasados españoles [...]" Esas noticias, como sabemos, constituyen la materia de la obra y versan sobre el conjunto de razones que han hecho perpetua, inacabable, la guerra de Chile. Lo relevante es que tales noticias, adquiridas mediante la estructura dialógica de la conversación con el Otro-indígena, configuran la contra argumentación derogadora de la guerra de conquista, de tal manera que son los sujetos que han padecido la experiencia horrorosa de la conquista y compartido una misma desdicha, los indios y el cautivo, los que entregan la razones para levantar el juicio contra el proceso histórico.

El principal blanco a que se han encaminado estos verdaderos discursos - como al principio tengo manifestado- ha sido significar las causas y fundamentos que hallo para la dilación de la guerra de Chile; y para que se conosca con evidencia que lo que digo y escribo en este volumen es por ciertas relaciones adquiridas de los propios antiguos naturales, he fundándolos en historia de mi cautiverio dichoso y feliz, por referir experimentado lo que adquirí cuidadoso entre los indios más ancianos, criados y nasidos en aquellos tiempos de los primeros conquistadores... Los capítulos pasados nos han servido de ponderar algunas causas atroces, inhumanas y ajenas de la piedad cristiana, que nos refirieron aquellos viejos caciques, estando en buena conversación, de la cual se han ido eslabonando las materias y puntos que se han tocado (Tomo II, 585).

En esta conversación, extendida a lo largo de toda la obra, los caciques exponen tres elementos que Núñez de Pineda establecerá como las tres causas fundamentales de la guerra y ruina de Chile. La primera, concerniente al orden espiritual, es la serie de crímenes y pecados cometidos por la evangelización conquistadora. Puntualmente, por los padres doctrineros y los 
encomenderos. La segunda es la corrupción generalizada de los gobernantes del establecimiento colonial. La tercera es la esclavitud inhumana de que son víctimas los naturales, sus mujeres y sus hijos. Fuera de estas razones, ya en el ámbito propiamente colonial, Pineda establece una cuarto elemento para que este reino sea en verdad un "laberinto de confusión": el gobierno de los "advenedizos extranjeros enemigos de la Patria" (Tomo II, 814), quienes despojan a los verdaderos "hijos de la tierra" (Tomo II, 817) de los oficios, cargos de gobierno y de las encomiendas, especialmente a aquellos que han sostenido el peso de la guerra de frontera.

El punto es que toda la perversión descrita por los naturales debe ser puesta en la perspectiva de la "policía cristiana" y en relación con su justificación trascendente del poder. En el ajuste del discurso teológico-civilizador con los hechos reales de la guerra de conquista relatados por los caciques, el juicio de Pineda es implacable. Aun cuando él mismo declara como uno de sus bienes más preciados su formación jesuita, refrenda la índole execrable de los primeros sacerdotes pertenecientes a esta orden y la conducta lasciva y corrupta de otros anteriores y posteriores a ellos. A los conquistadores los mide con la misma vara, pues a las traiciones de los evangelizadores se suman las tropelías, violaciones, abusos sexuales y asesinatos de los primeros españoles y sus mujeres, quienes además secuestraban a las jóvenes y a los jóvenes indígenas para marcarlos con fuego en la cara y "venderlos como a negros" en el puerto de Valdivia (Tomo II, 714-718). Lo significativo aquí es que el relato indígena de estas perversiones es apropiado por Pineda como razón individual, y por lo tanto, como fundamento propio para invalidar el proceso de evangelización del Reino de Chile.

De aquí podremos sacar dos cosas a nuestro intento: lo primero, que la iglecia y su vicario no puede dar permiso para que a fuerza de armas se conquistasen estos infieles, y si por lo dicho no tuvo potestad para hacerlo, y el permiso que dio fue no con la intención de guerra, que por los primeros conquistadores se ejecutó, seguiráse de aquí no haber sido justificada esta guerra; lo segundo, que, habiendo entrado conquistando a fuerza de armas, con muertes, destrosos y vertida sangre de muchos, la fee que admitieron fue sin ninguna luz de nuestro Dios ni de nuestra religión cristiana, así por el temor que cobraron a los españoles, como por el mal ejemplo con que fueron industriados; que antes pudiéramos decir que los enseñaron a blasfemar a Dios [...] 


\section{$[\ldots]$}

bien podemos decir que a estos pobre infieles no los enseñaron, sino fue a blasonar [blasfemar] a Dios, Nuestro Señor, como dice san Crisóstomo, y a fuerza de armas y rigores los hisieron cristianos, y lo fueron de cumplimiento y sólo en el nombre, porque con palabras querían parecer ministros de Cristo, Señor Nuestro, y con sus perversas obras embajadores y ciervos de Zatanás (Tomo II, 691).

Si el asunto es que los hechos denunciados desvinculan a los evangelizadores, conquistadores y encomenderos de la "policía cristiana" y su justificación del poder en el linaje de la justicia, la consecuencia es que el proceso completo de la conquista de Chile queda fuera del orden universal. El quiebre del vínculo entre el poder terreno y la donación divina es, precisamente, aquello que gesta la ruina como origen, o el mundo arruinado al que hicimos mención unos párrafos más atrás. Sobre todo, es aquello que establece la equivalencia entre la ruina de la cristiandad y la ruina originaria del reino de Chile. Desde la perspectiva de la conciencia moderna, es lo que formula una suerte de "fin de civilización" y compele una reescritura de la historia.

Esta también sin duda es la causa de que este reino de Chile, y aun todos los de las Indias, a más andar vayan caminando a bosque, pues lo más de nuestras antiguas poblaciones no son hoy otra cosa que espesos montes y desiertas selvas: díganlo los edificios de la ciudad de Chillán, los de Arauco, San Felipe, San Cristóbal, San Rosendo, y otras más de cuatrocientas estancias populosas, que sus suntuosas casas y edificios con las de las ciudades competían: todo esto ¿no es hoy una montaña y un tupido y cerrado bosque inhabitable, porque le han echado leña sin haberla menester?; y la ciudad de La Concepción, que sirve hoy de frontera, ¿en qué estado diremos que se halla? (945).

Un poco más adelante, la lamentación de la conciencia chilena del desengaño:“¡Ay de vosotros los de las Indias!: hay pocos que nos digan, por cuya causa podré decir yo llorando: jay de ti Chile, y ay de nosotros!” (Tomo II, 701).

Si bien la disolución y borramiento de la obra humana por la naturaleza entrega una visión muy interesante de la ruina, en este momento nos interesa volver sobre el vínculo quebrado entre el gobierno de la monarquía y la divinidad. El asunto atrae aquí un axioma medular de la "policía cristiana", tal cual es la representatividad divina del príncipe y su justificación primera y última en el poder. Según este imperativo, a imitación del que gobierna "todo el universo y lo creado", el príncipe debe guiar a su pueblo como si él mismo 
fuese un dios en la tierra. Es decir, imitando la perfectísima justicia, caridad y misericordia con que Dios guía su pueblo. A lo anterior, Pineda agrega otro elemento sensible a toda su argumentación: que Dios cedió su potestad y mando a su Hijo Unigénito, no porque este compartiera su naturaleza divina, sino por haber padecido trabajos de hombre entre los hombres (Tomo I, 76). Puesto el acento en esto último, señala a la Corona su proceder equivocado en cuanto no atiende el mérito por el trabajo, sino que designa en los puestos administrativos y de poder a aquellos que presentan mejores memoriales y peticiones según la diestra mano de los leguleyos. Esto significa que desde la base del orden cristiano, la Corona y sus designados no proceden a la imitación de Dios, no se comportan en ningún sentido como "dioses en la tierra" (Tomo I, 76). Perdido el vínculo por imitación, resulta que toda la estructura de gobierno de las Indias no tiene fundamento, al menos, no el que dice tener. La primera imagen del monarca es, entonces, la de un sol limitado, poco potente o indiferente, cuyos rayos no llegan a todo el territorio de la monarquía y no alcanzan a disipar las "nieblas tenebrosas" de su ruina (61). La segunda, ya al final de la obra, es la imagen degradada del gobierno de Indias como un teatro de comedia, en el cual los gobernadores, vaciados del vínculo fundamental, adquieren la condición de figuras:

...que no les ha de durar el mando, ni han de gobernar para siempre, porque, como dijo Pedro Gregorio, el príncipe o gobernador hace un papel de comedia y una figura como de representante que se viste de rey, y a la noche deja la vestidura real y se queda como los demás; y esto acontece más propiamente en estos remotos reinos de las Indias, por estar dilatados y más a lo largo de la presencia del rey, nuestro señor, adonde le usurpan la potestad que tiene, y en su asistencia y a su vista son unas figuras de comedia (Tomo II, 921).

Los gobernantes de las Indias son unas figuras de comedia de otra figura de comedia vaciada porque permite la perpetuación de una guerra injusta. Con esta imagen barroca, Núñez de Pineda y Bascuñán describe el teatro del poder y su vaciamiento en el "nuevo mundo", particularmente en la Capitanía de Chile. En el borde de ese vacío, los personajes que dialogan son el Otroindígena y el cautivo-criollo, las dos conciencias negativas del barroco oscuro del Reino de Chile; las dos conciencias modernas que emergen después de la caída utópica de la cristiandad: los dos testigos de esa caída.

Partimos señalando que la cuestión del género en esta obra implicaba una sincronía entre el "sentido de la subjetividad" y el "sentido de la historia". La 
indagación en la índole de esa coincidencia no solo ha mostrado la profunda politicidad de las letras coloniales chilenas, irreducible solamente a una disquisición literaria. Muestra además la complejidad de una conciencia que padece el trauma de la guerra y polemiza el vacío de un orden que dé sentido a esa guerra. De tal manera que la sincronía entre conciencia e historia tiene un denominador común: la guerra injusta que inaugura la modernidad americana.

\section{BIBLIOGRAFÍA}

Anónimo. La Guerra de Chile. Santiago de Chile: Biblioteca Antigua Chilena, 1996.

Arias de Saavedra, Diego. Purén Indómito. Seminario de Filología Hispana. Santiago de Chile: Ed. La Noria, 1984.

Bello, Andrés (1862). "La araucana por don Alonso de Ercilla i Zúñiga - Juicio crítico de esta obra por el Señor Rector de la Universidad don Andrés Bello". Anales de la Universidad de Chile, doi: 10.5354/0717-8883.2010.2476.

Blanchot, Maurice. La escritura del desastre. Trad. de Cristina Peretti y Luis Ferrero Carracedo. Madrid: Trotta, 2015: 12.

De Oña, Pedro. Arauco Domado. Ed. J. T. Medina. Santiago de Chile: Imprenta Universitaria, 1917.

Didi-Huberman, George. Pueblos expuestos, pueblos figurantes. Trad. Horacio Pons. Buenos Aires: Manantial, 2014.

Ferrecho, Mario y Raïssa Kordić Riquelme. Estudio preliminar de Cedomil Goic. Biblioteca Antigua Chilena, Facultad de Filosofía y Humanidades, Universidad de Chile, Santiago, 2001.

Invernizzi, Lucía. "Ercilla, narrador de La Araucana". En Memoria poética. Reescrituras de La Araucana. Ed. Luz Ángela Martínez y Jaime Huenún. Santiago de Chile: Cuarto Propio, 2010, pp. 39-62.

López de Gómora, Francisco. Historia general de Las Indias. Tomo I. Madrid: Espasa Calpe, 1922. 5 .

Núñez de Pineda y Bascuñán, Francisco. Cautiverio Feliz. Edición Crítica de Mario

Ricoeur, Paul. Historia y verdad. Argentina: Fondo de Cultura Económica, 2015.

Texto, testimonio y narración. Santiago de Chile: Editorial Andrés Bello, 1983.

White, Hayden. El texto literario como artefacto histórico. Barcelona: Ediciones Paidós, 2003. 